\title{
Reflexões sobre o comportamento do consumidor e o cartão de crédito no Brasil
}

Adriana Sbicca*

André Luiz Fernandes**

\begin{abstract}
RESUMO - Este artigo apresenta o enfoque da economia comportamental (Behavioral Economics) para o estudo da utilização de cartão de crédito pelo consumidor. Forma de pagamento mais utilizada, o cartão de crédito é o maior responsável pelo endividamento das famílias. A entrada em vigor da Resolução 3.919/2010 do Conselho Monetário Nacional e da Circular 3.512/2010 do Banco Central do Brasil, que trouxeram novas regras ao mercado, mostra que o Estado brasileiro encontra-se atento ao papel desses instrumentos financeiros. Entretanto, a análise revela que a legislação dos EUA para este mercado, particularmente o Credit Card Act, incorporou mais amplamente as contribuições da economia comportamental que a normatização brasileira.
\end{abstract}

Palavras-chave: Economia comportamental. Regulação. Cartão de crédito.

\section{INTRODUÇÃO}

A inflação volta a ser uma das preocupações principais e o controle do crédito ao consumidor é visto como uma política importante para diminuir as pressões de demanda sobre os preços. O crédito em expansão estimula o consumo e o Governo tem aumentado seus custos. A subida da taxa SELIC tem sido frequente e, em abril último, o Imposto sobre Operações Financeiras (IOF), que incide sobre o crédito a pessoa física, foi elevado em 1,5\%, passando a 3\%. Além disso, houve a elevação do compulsório. Os efeitos das medidas adotadas serão sentidos, espera-se, dentro de seis a nove meses, mas já é possível observá-los. A demanda por crédito ainda está em crescimento mas tem se reduzido e sua taxa de crescimento apresentou queda, de março para abril, de cerca de $3 \%$.

Aumentou o grau de endividamento das famílias. No mês de abril, 64,2\% das famílias declararam-se endividadas, contra 58,7\% em abril de 2010, segundo Pesquisa Nacional de Endividamento e Inadimplência do Consumidor (PEIC) divulgada pela CNC (Confederação Nacional do Comércio de Bens, Serviços e Turismo). Entre os meses de março e abril de 2011

\footnotetext{
*Doutora em Economia de Empresas pela Escola de Economia de São Paulo - Fundação Getúlio Vargas. É professora do Departamento de Economia da Universidade Federal do Paraná. Endereço eletrônico: adsbicca@ufpr. br.

** Mestre em Desenvolvimento Econômico pela Universidade Federal do Paraná. Bacharelando em Direito pela Universidade Federal do Paraná. É analista de controle do Tribunal de Contas do Estado do Paraná. Endereço eletrônico: aluiz@tce.pr.gov.br.
} 
ocorreu uma elevação no endividamento de 1,6\%. O grau de endividamento do consumidor ainda apresenta crescimento, o que contribui para o aumento do número daqueles que têm contas em atraso: $24,4 \%$ das famílias, em maio. O dado positivo é que houve redução em relação a maio de 2010, quando 25,1\% das famílias declararam ter dívidas em atraso.

A principal fonte de endividamento apontada pelo Instituto de Defesa do Consumidor (IDEC) é o cartão de crédito, e esta é a forma de pagamento que mais cresce no país. No comparativo dos custos do crédito praticados, o crédito rotativo do cartão de crédito faz uso dos juros mais elevados, mais altos que os do cheque especial que, por sua vez, são superiores aos do crédito pessoal.

De acordo com o Bacen, a quantidade de cartões de crédito evoluiu de 53,5 milhões (média de 1 cartão para cada 3,4 habitantes), em 2004, para 137,8 milhões em 2008 (média de 1 cartão para cada 1,4 habitantes), uma variação da ordem de 157,6\% no período (crescimento médio de 26,7\% ao ano). Em 2008, foram efetuadas cerca de 2,5 bilhões de transações, no valor global de cerca de $\mathrm{R} \$ 217,9$ bilhões, com valor médio de cerca de $\mathrm{R} \$ 86,00$ por transação. No período entre 2004 e 2008, as transações com cartão de crédito cresceram 101,2\% em quantidade, numa média de 19,1\% ao ano. O crescente uso dos cartões de crédito, juntamente com o aumento do endividamento, colocaram em alerta economistas e juristas, o que levou os EUA e o Brasil a buscarem o aperfeiçoamento da regulação do mercado de cartões de crédito.

$\mathrm{Na}$ decisão racional sustentada pela teoria tradicional, os consumidores levariam em consideração os custos e benefícios do seu conjunto de alternativas possíveis e optariam por diminuir os primeiros e aumentar os segundos. A utilização do crédito rotativo do cartão de crédito, cujo benefício é o consumo imediato ao invés de postergado mas que apresenta o maior custo relativo do mercado, é difícil de ser explicada por esse arcabouço teórico tradicional da economia. Em tempos de juros altos, pague à vista, diriam conselhos mais ponderados. Mas os dados mostram que a procura por crédito aumenta, e justamente através do instrumento que pratica os mais altos juros. Outras percepções usuais reforçam a preocupação com a regulação desta forma de pagamento. Como exemplo, temos a sensação de que a posse de um cartão de crédito funciona como um estímulo ao consumo.

De que forma podemos melhor compreender os efeitos descritos acima? Contribuições da economia comportamental sugerem respostas a essa questão. Diversas decisões poderiam ser melhor compreendidas com a incorporação de elementos explicativos sugeridos por essa abordagem e muitos comportamentos entendidos como anômalos na economia, por serem diferentes dos comportamentos racionais esperados pela teoria econômica tradicional, poderiam ser melhor explicados pela economia comportamental. 


\section{ALGUMAS CONTRIBUIÇÕES DA ECONOMIA COMPORTAMENTAL}

Ganhador do prêmio Nobel de Economia de 1978, Herbert Simon tem uma vasta produção acadêmica cujo foco encontra-se nas decisões humanas e na abordagem de racionalidade denominada "racionalidade limitada". Ele tratou da influência sobre as decisões exercida pela complexidade do ambiente em que a decisão ocorre e pelos limites cognitivos do ser humano. Simon salientou que, dentre os mecanismos usados para facilitar o processo decisório, o mais importante é o uso de heurísticas: regras que simplificam a tomada de decisão (SIMON, 1980). O seu estudo teve como ponto de partida o enxadrista. Ele percebeu que o jogador de xadrez mais habilidoso não se diferenciava por ter maior capacidade de memorizar longas sequências de jogadas para então decidir, dentre todas as alternativas possíveis de movimento, a jogada que maximizasse o resultado. Mas sim, por ter em mente padrões de jogada. Graças a essa habilidade, os mestres enxadristas podem se utilizar de mais dicas estocadas e conhecimentos associados para resolver problemas. Muitas vezes, os experts retomam informações da memória que os ajudam na resolução até mesmo sem análise consciente. Simon e Schaeffer (1989) sustentaram que adquirir conhecimento não é simplesmente aumentar a quantidade de "fatos" de que se tem notícia; ao contrário, isso exige em grande parte desenvolver a capacidade de criar categorias e padrões, muitas vezes de maneira aproximada, nos quais se organizam e se estocam as percepções.

A partir dos anos 1970, Tversky e Kahneman, dois psicólogos, elaboraram a abordagem conhecida como "heurísticas e desvios" e atraíram a atenção da academia, o que levou ao Nobel de Economia de Kahneman, em 2002ㄹ. Vários autores foram influenciados pela aceitação crescente de que os comportamentos chamados anômalos poderiam ser explicados pela economia comportamental e essa abordagem passou a ser utilizada na análise de muitos eventos empíricos em administração, direito, economia e medicina. Através dos diversos experimentos que Kahneman e Tversky desenvolveram, eles observaram comportamentos que chamaram de desvios, por fugirem ao que seria esperado de agentes racionais como postulado pela teoria econômica mais tradicional. Segundo eles, a percepção das pessoas é influenciada por diversos atributos tais como a saliência, que se refere tanto à medida de uma característica quanto à intensidade e diagnóstico: brilho de luz, volume de um som, saturação de uma cor, o tamanho de uma carta, a frequência de um item, a nitidez de uma imagem (TVERSKY, 1977; TVERSKY; GATI, 1978).

Como Simon, também Kahneman e Tversky observaram que heurísticas são comu-

1 Amos Tversky faleceu em 1996, o que o tornou inelegível ao prêmio, mas Kahneman em seu Nobel-lecture afirmou que foi o trabalho em conjunto que ganhou o prêmio. 
mente usadas pelo ser humano para facilitar suas decisões. Esses autores explicaram os desvios de comportamento através de heurísticas utilizadas pelo decisor. Argumentavam os autores que muitas decisões são baseadas em crenças construídas a respeito de fatos e/ou processos que não são conhecidos com certeza. Diante de situações como essas, as pessoas fazem uso de regras simples que reduzem a complexidade das decisões. Para eles, "Em geral, estas heurísticas são totalmente úteis, mas algumas vezes elas levam a erros graves e sistemáticos." (TVERSKY; KAHNEMAN, 1974, p. 1124). Kahneman e Tversky distinguiram essas regras sendo as mais comuns a heurística da representatividade, da disponibilidade e da ancoragem (TVERSKY; KAHNEMAN, 1983). A heurística da representatividade é bastante usada por enxadristas e também pelas pessoas quando elas fazem inferências para uma população a partir de amostra(s). Como consequência do uso da heurística da representatividade, Kahneman e Tversky perceberam que as pessoas muitas vezes aplicam indevidamente a Lei dos Grandes Números a amostras pequenas (TVERSKY; KAHNEMAN, 1971). Essa lei, muito utilizada na estatística, sustenta que uma amostra grande apresenta características da população. O resultado esperado pelas pessoas no tradicional cara ou coroa é um exemplo de um desvio provocado pelo uso da heurística da representatividade: as pessoas esperam que a sequência de eventos de cara e coroa de uma moeda sem vício seja próxima a 50\% para cara e 50\% para coroa, mesmo numa sequência pequena (TVERSKY; KAHNEMAN, 1974, p. 1125). Assim, depois de três lançamentos com resultado "cara", as pessoas esperam que o quarto lançamento resulte em "coroa". E passam a duvidar da confiabilidade da moeda caso isso não ocorra. A Lei dos Grandes Números, no entanto, não sustenta algo semelhante para amostras pequenas, ou seja, nem todos os segmentos de sequências obtidos do lançamento de uma moeda serão altamente representativos da confiabilidade da mesma. Aparentemente, afirmaram Tversky e Kahneman (1971, p. 106), os jogadores esperam que algum desvio em uma direção será brevemente cancelado pelo correspondente desvio na direção oposta. Mas não é assim que se passa. Imagine que seja adicionada uma colher de café de um ingrediente errado a uma receita: se a panela for pequena este erro será notado. Se a panela é grande, não. Ou seja, os erros não são cancelados nas amostras, mas simplesmente diluídos.

Outra regra documentada por Kahneman e Tversky é a heurística da disponibilidade: uso que as pessoas fazem das informações que lhes veem mais facilmente à mente, seja porque são mais recentes, seja porque são mais marcantes. $\mathrm{O}$ uso desta regra pode explicar o fato das pessoas tenderem a superestimar a probabilidade de eventos que ocorreram recentemente em relação àqueles que aconteceram há mais tempo, como o medo de viajar de avião devido à ocorrência de um acidente recente ou o aumento da procura por seguro logo após um 
terremoto ou um incêncio (JOHNSON et al., 2000). As chances de acontecer acidente de avião, terremoto ou incêndio não são aumentadas devido à ocorrência de um evento recente, mas as decisões das pessoas tenderão a superestimá-las em função de estarem "vivos" na mente esses fatos.

O uso da heurística da ancoragem, também chamada de ancoragem e ajustamento, faz com que a decisão seja influenciada pela ordem em que os dados são apresentados ao decisor, que usa como referencial algo que primeiro lhe é apresentado para ajustar, a partir dele, as outras informações. Uma informação inicial, ou âncora, tende a exercer uma influência maior, levando a escolha final a estar próxima a essa âncora inicial (TVERSKY; KAHNEMAN, 1974). Quando perguntadas se a população brasileira é maior ou menor que 100 milhões e, depois, qual é a população brasileira, as pessoas tendem a estimar um valor próximo a 100 milhões. Se a pergunta inicial tivesse sido se o Brasil tem uma população maior ou menor que 200 milhões, as pessoas tenderiam a responder à segunda questão com um valor próximo a 200 milhões. As diferenças de respostas se relacionam à ancoragem aos valores utilizados nas perguntas, que atraem as estimativas que as pessoas fazem para efetuarem a resposta.

Outra contribuição da economia comportamental é o chamado comportamento míope. Este efeito propõe uma explicação para a dificuldade de postergação do consumo. Tem sido documentado que os benefícios de curto prazo possuem um peso muito maior na escolha do consumidor do que os custos que incidirão mais tarde. Esse comportamento "míope" decorre da inclinação, tanto do indivíduo como das organizações, de dar mais importância ao curto que ao longo prazo. Como sustentado por Levinthal e March (1993), uma organização tende a preferir pequenos benefícios no curto prazo que maiores benefícios no longo prazo. Da mesma forma, são preferidas maiores perdas no futuro que menores perdas no presente. $\mathrm{O}$ indivíduo também manifesta essa tendência trocando perdas pequenas e imediatas por perdas maiores mais distantes no tempo.

\section{O CARTÃO DE CRÉDITO E A ESCOLHA DO CONSUMIDOR}

Estas contribuições da economia comportamental podem ajudar a explicar a escolha do consumidor ao utilizar o produto financeiro com maior custo comparativo - no caso, o cartão de crédito. Utilizando-se a ideia de miopia, temos que o prazer do consumo imediato é muito mais importante para o consumidor do que os custos (a dor) do pagamento posterior (dor aumentada pelos juros que deverão ser pagos).

A economia comportamental ainda apresenta outras contribuições para a compreensão da influência do cartão de crédito sobre a decisão de consumo. O fato da compra ficar 
separada do pagamento, e antes dele, torna a quantia paga pelo bem menos saliente e o consumidor mais disposto a efetuar a compra (THALER, 1999, p. 193). Assim, o consumidor é mais sensível a (se incomoda mais de) pagar $\mathrm{R} \$ 50,00$ no ato da compra do que pagar depois. Ele também está menos disposto a pagar em dinheiro do que com cartão de crédito.

$\mathrm{Na}$ abordagem mais tradicional da decisão econômica, o papel do ofertante deve ser de disponibilizar todas as informações relevantes para o consumidor tomar sua decisão. Isso asseguraria a boa decisão, já que o consumidor utiliza todas as informações disponíveis para maximizar sua utilidade. Mas a saliência pode ser muito mais relevante para a decisão do que apenas a disponibilidade ou não da informação. Os juros dos cartões de crédito são apresentados na fatura (a informação está disponível), mas grande parte das pessoas opta por essa modalidade de crédito, apesar dos altos custos (informações que possam levar o consumidor a refletir sobre a dificuldade de pagamento dos altos juros podem não estar salientes).

Nos EUA, vem se desenvolvendo um longo debate no Legislativo sobre a importância da percepção sobre a decisão de uso do cartão de crédito. A forma de apresentação da fatura do cartão de crédito ganhou destaque, particularmente sobre a influência que a informação de pagamento mínimo exerce sobre as pessoas que não efetuam o pagamento total da fatura. Stewart (2009) mostrou que ocorre um efeito, pelo uso da heurística de ancoragem, que aumenta a tendência das pessoas de pagarem a fatura pelo mínimo, mesmo quando não necessitariam fazê-lo.

Em fevereiro de 2010 o Credit Card Act aperfeiçou a legislação de regulação do mercado de cartões de crédito dos EUA. A partir da vigência das novas regras, as empresas de cartão de crédito estão obrigadas a disponibilizar as faturas com, no mínimo, 21 dias de antecedência sobre a data de vencimento, discriminando, além de estimativas de fluxos de pagamentos para o caso do consumidor optar por efetuar o pagamento mínimo, avisos destacados sobre os efeitos do pagamento mínimo sobre a dívida total e do eventual atraso no pagamento da fatura. Os termos utilizados na redação da nova legislação procuram deixar evidente a obrigatoriedade das operadoras de cartão de crédito de fornecerem de forma concisa, precisa e completa as informações necessárias à tomada de decisão do consumidor, determinando inclusive sua apresentação em formato de tabela e proibindo que seja necessária a remissão a documentos externos para que se possa ter a compreensão total dos dados tabulados. Percebe-se uma clara preocupação da lei com a forma de apresentação das informações, o que denota na mesma a consideração dos efeitos da heurística da ancoragem sobre o comportamento do consumidor. Surgiu também, naquele país, uma preocupação crescente com os avanços da indústria de cartão de crédito sobre os adultos jovens e sobre os estudantes universitários. Em face desses 
últimos, ocorreu a proibição das operadoras de cartão de crédito de promoverem seus produtos através de brindes nas proximidades de instituições de nível superior ou mesmo de eventos por elas promovidos ou patrocinados.

Apesar das inúmeras diferenças entre a regulação norte-americana e brasileira, que refletem peculiaridades dos dois mercados, há alguns pontos comuns que merecem ser destacados. O pagamento mínimo é preocupação nos dois países em função da sua potencialidade para tornar a dívida insustentável devido à incidência dos juros. Também há grande preocupação para tornar mais transparente ao usuário o significado das operações financeiras nas quais ele está sendo engajado quando opera com os cartões de crédito.

No Brasil, em maio de 2010, ocorreu um seminário no qual o Presidente do Banco Central, Alexandre Tombini, apresentou as novas regras de cartão de crédito propostas pela Comissão Monetária Nacional e construídas pelo trabalho conjunto com os Ministérios da Fazenda e da Justiça e o Ministério Público Federal. Segundo ele, essas medidas têm o intuito de assegurar a sustentabilidade e transparência desse instrumento que tem apresentado grande crescimento. Essas medidas também têm o objetivo de incentivar "o uso mais racional desse meio de pagamento, ajudando a evitar que as famílias se endividem em excesso". A partir de $1^{\circ}$ de junho de 2011, o pagamento mínimo do cartão de crédito será de 15\% do valor total e este montante será elevado a $20 \%$ a partir de dezembro do mesmo ano. Apenas cinco tarifas poderão ser cobradas, o que representa uma enorme redução em relação às mais de oitenta antes existentes. Serão elas: anuidade, emissão de segunda via, saque, pagamento de contas no cartão e avaliação emergencial de limite de crédito. Segundo Tombini, a grande quantidade de tarifas existentes dificultava a compreensão do usuário final dos cartões e levava a uma relação hostil entre prestador de serviço e usuário. Na determinação da nova normatização, houve uma preocupação especial em informar o usuário sobre os encargos do não pagamento total da fatura. Ainda que signifique um avanço, essa preocupação tem como base mais uma visão quanto à disponibilidade de informação do que quanto às características da influência da percepção do agente sobre sua decisão.

\section{CONSIDERAÇÕES FINAIS}

Há, ainda, uma grande distância entre o debate que ocorre nos EUA e o do Brasil, mas o cartão de crédito começa a receber a atenção da regulação brasileira. Ainda falta ressaltar, por exemplo, o estímulo ao consumo e ao uso do crédito rotativo devido à saliência de algumas informações. Também a relação entre a indústria de cartões de crédito e o público adulto jovem e o universitário parece merecer atenção dos pesquisadores para que seja avaliada a necessidade 
de políticas para esta categoria específica de consumidores, como já ocorre nos EUA.

A economia comportamental, seja em sua vertente da Behavioral Economics ou da Behavioral Law and Economics, se apresenta como uma visão alternativa àquela sustentada pela teoria econômica tradicional e traz um potencial explicativo a ser considerado ao se buscar um aprofundamento da reflexão sobre a decisão de consumo com utilização de crédito.

\section{REFERÊNCIAS}

CREDIT card accountability responsibility and disclosure act of 2009. Disponível em: < http://www.gpo.gov/fdsys/pkg/PLAW-111publ24/html/PLAW-111publ24.htm>.

DISCURSO de Alexandre Antonio Tombini, na abertura do seminário sobre novas regras de cartões de crédito. Disponível em: <http://www.bcb.gov.br/pec/appron/apres/Discurso\%20 do $\% 20$ Presidente $\% 20$ do $\% 20 \mathrm{Banco} \% 20$ Central $\% 20 \mathrm{do}^{2} \% 20 \mathrm{Brasil} \% 20$ Alexandre $\% 20$ Antonio $\% 20$ Tombini, $\% 20$ na $\% 20$ abertura $\% 20 \mathrm{do} \% 20$ Semin $\%$ C3 $\%$ A 1 rio $\% 20$ sobre $\% 20$ Novas $\% 20$ Reg ras $\% 20 \mathrm{de} \% 20 \mathrm{Cart} \% \mathrm{C} 3 \% \mathrm{~B} 5 \mathrm{es} \% 20 \mathrm{de} \% 20 \mathrm{Cr} \% \mathrm{C} 3 \%$ A 9 dito..pdf>. Acesso em: 30/5/2011.

JOHNSON, E. J.; HERSHEY, J.; MESZAROS, J.; KUNREUTHER, H. Framing, probability distortions, and insurance decisions. In: KAHNEMAN, D.; TVERSKY, A. (Ed.). Choices, values and frames. Cambridge University Press, 2000.

LEVINTHAL, D. A.; MARCH, J. G. The myopia of learning. Strategic Management Journal, v. 14, special issue: Organizations, decision making and strategy, p. 95-112, 1993.

SIMON, H. A. Invariants of Human Behavior. Annual Review of Psychology, v. 41, p. 1-19, 1990.

SIMON, H. A.; SCHAEFFER, J. The game of chess. In: AUMANN, R. J.; HART, S. (Ed.), Handbook of game theory with economic applications. Amsterdam: North-Holland, v. 1, p. 1-17, 1989.

STEWART, N. The cost of anchoring on credit-card minimum repayments. Psychological Science, v. 20, n. 1, p. 39-41, jan. 2009.

THALER, R. H. Mental accounting matters. Journal of Behavioral Decision Making, v. 12, p. 183-206, 1999.

TVERSKY, A. Features of similarity. Psychological Review, v. 84, p. 327-352. Reprinted in SHAFIR, E. (Ed.). Preference, belief, and similarity - selected writings Amos Tversky. Cambridge, MA and London: MIT Press, p. 7-46, 1977.

TVERSKY, A.; GATI, I. Studies of similarity. In: ROSCH, E.; LLOYD, B. (Ed.). Cognition and categorization, p. 79-98, Hillsdale: Erlbaum. Reprinted in: SHAFIR, E. (Ed.). Preference, belief, and similarity - selected writings Amos Tversky. Cambridge, MA and London: MIT Press, p. 75-95, 1978.

TVERSKY, A.; KAHNEMAN, D. Belief in the law of small numbers. Psychological Bulletin, v. 76, n. 2, p. 105-110, 1971.

TVERSKY, A.; KAHNEMAN, D. Judgment under uncertainty: heuristics and biases. Science - New Series, v. 185, n. 4157, p. 1124-1131, 1974.

TVERSKY, A.; KAHNEMAN, D. Extensional versus intuitive reasoning: the conjunction fallacy in probability judgment. Psychological Review, v. 90, n. 4, p. 293-315, 1983. 